LUIZ Francisco Baccaro ${ }^{1}$

ILKA dE FÁtIMA BOIN²

LÚCIA COSTA-PAIVA ${ }^{1}$

Aline Garcia Leal ${ }^{3}$

Celso Dario Ramos ${ }^{3}$

Aarão Mendes Pinto-Neto'

Original Article

Keywords

Osteoporosis

Liver transplantation

Menopause

Palavras-chave

Osteoporose

Transplante de fígado

Menopausa

\section{Is liver transplantation associated with decreased bone mass in climacteric women?}

\author{
O transplante bepático está associado a menor massa óssea em \\ mulheres climatéricas?
}

Abstract

PURPOSE: To evaluate whether climacteric women undergoing liver transplantation had higher prevalence of decreased bone mass than those without any liver disease. METHODS: A cross-sectional study with 48 women receiving follow-up care at a university hospital in Southeastern Brazil, from February $4^{\text {th }} 2009$ to January $5^{\text {th }} 2011$, was conducted. Of these women, 24 were 35 years or older and had undergone liver transplantation at least one year before study entry. The remaining 24 women had no liver disease and their ages and menstrual patterns were similar to those of transplanted patients. Laboratorial tests (follicle-stimulating hormone and estradiol) and bone density measurements of the lumbar spine and femur (equipment Hologic, Discovery WII were performed. Statistical analysis was carried out by Fisher's exact test, simple Odds Ratio (OR), and multiple logistic regression. RESULTS: Mean age of the women included in the study was $52.8( \pm 10.7)$ years-old, $27.1 \%$ were premenopausal and $72.9 \%$ were peri/postmenopausal. Approximately $14.6 \%$ of these women exhibited osteoporosis and $35.4 \%$ had low bone mass. The following items were associated with decreased bone mass: being postmenopausal $(O R=71.4$; 95\% Cl 3.8-1,339.7; $p<0.0001)$, current age over 49 years-old $(O R=11.4 ; 95 \% \mathrm{Cl} 2.9-44.0 ; p=0.0002)$, and serum estradiol levels lower than $44.5 \mathrm{pg} / \mathrm{mL}(\mathrm{OR}=18.3 ; 95 \% \mathrm{Cl} 3.4-97.0 ; p<0.0001)$. Having a history of liver transplantation was not associated with decreased bone mass (OR=1.4; $95 \% \mathrm{Cl} 0.4-4.3 ; p=0.56)$. CONCLUSION: Liver transplantation was not associated with decreased bone mass in this group of climacteric women.

\section{Resumo}

OBJETIVO: Avaliar se mulheres climatéricas submetidas a transplante de fígado tiveram maior prevalência de massa óssea diminuída do que aquelas sem antecedente de doença hepática. MÉTODOS: Estudo de corte transversal, com 48 mulheres em acompanhamento ambulatorial em um hospital universitário na região Sudeste do Brasil, no período de 04 de fevereiro de 2009 a 05 de janeiro de 2011 . Foram incluídas 24 mulheres submetidas a transplante hepático há pelo menos um ano, com idades igual ou superior a 35 anos, e 24 sem antecedente de doença hepática, com idade ( \pm três anos) e padrão menstrual semelhante ao das transplantadas. As mulheres foram submetidas a exames laboratoriais (hormônio folículo estimulante e estradiol) e à densitometria óssea de coluna lombar e fêmur, com equipamento Hologic, Discovery WI. A análise estatística foi realizada por meio do teste exato de Fisher, por Odds Ratio (OR) simples e pela regressão logística múltipla. RESULTADOS: A média etária das mulheres incluídas no estudo foi de 52,8 ( $\pm 10,7)$ anos, sendo que $27,1 \%$ estavam na pré-menopausa e 72,9\%, na peri/pós-menopausa. Aproximadamente $14,6 \%$ dessas mulheres apresentaram osteoporose e 35,4\%, baixa massa óssea. Os seguintes itens foram associados com massa óssea diminuída: estar na pós-menopausa (OR=71,4; IC95\% 3,8-1.339,7; $p<0,0001)$, idade atual maior que 49 anos $(O R=11,4 ; \mid C 95 \% 2,9-44,0 ; p=0,0002)$ e nível de estradiol sérico menor que 44,5 pg/mL (OR=18,3; IC95\% 3,4-97,0; $p<0,0001)$. Ter antecedente de transplante hepático não se associou à massa óssea diminuída $\mid \mathrm{OR}=1,4 ; \mathrm{IC} 95 \%$ 0,4-4,3; $\mathrm{p}=0,5)$. CONCLUSÃO: $\bigcirc$ transplante hepático não se associou à massa óssea diminuída nesse grupo de mulheres climatéricas.
Correspondence Luiz Francisco Baccaro Department of Tocogynecology, Universiddade Estadual de Campinas Avenida Alexander Fleming 101 - Cidade Universitárí Zeferino Vaz Zip code: 13083-881 Campinas (SP), Brazil

Received

$06 / 26 / 2012$

Accepted with modifications

$07 / 20 / 2012$
Study carried out at the Department of Tocogynecology, Woman Hospital Professor Doutor José Aristodemo Pinotti - CAISMUNICAMP - Campinas (SP), Brazil.

'Department of Tocogynecology, Faculdade de Ciências Médicas, Universidade Estadual de Campinas - UNICAMP - Campinas (SP), Brazil. 2 Departament of Surgery, Faculdade de Ciências Médicas, Universidade Estadual de Campinas - UNICAMP - Campinas (SP), Brazil. 3Departament of Radiology, Faculdade de Ciências Médicas, Universidade Estadual de Campinas - UNICAMP - Campinas (SP), Brazil. Conflicts of interest: none. 


\section{Introduction}

Osteoporosis is considered an important complication after liver transplantation ${ }^{1}$. The majority of patients who had liver transplantation develop accelerated bone mineral density (BMD) loss in the first three to six months following transplantation leading to increased fracture risk, owing to preexisting chronic liver disease associated with postsurgical administration of high doses of immunosuppressant agents ${ }^{2}$. Other factors, such as malnutrition, hypogonadism, vitamin D deficiency and physical inactivity, common in patients with end-stage liver disease, may also contribute to loss of bone mineral density $^{3}$. Furthermore, cholestatic diseases, such as primary biliary cirrhosis and sclerosing cholangitis, have also been described as risk factors for decreased bone mass due to possible malabsorption of calcium and vitamin $\mathrm{D}$ and interference of hyperbilirubinemia in the osteoblast function ${ }^{4}$. In contrast, a more recent study suggested that the introduction of boneprotective therapy and the reduction in the total dose of glucocorticoids used for immunosupression might lead to decreased incidence of fractures in patients undergoing liver transplantation ${ }^{5}$.

Women currently represent approximately onethird of patients who undergo liver transplantation. Primary biliary cirrhosis, cirrhosis following viral hepatitis, and autoimmune hepatitis are the main indications for liver transplantation in women ${ }^{6}$. Alcoholism and hepatitis $\mathrm{C}$ are also important indications in Brazil ${ }^{7}$. Climacteric women have a marked reduction in the serum estrogen levels, which is associated with decreased bone mass after menopause. A previous study including women with a history of liver transplantation aged $>35$ years-old demonstrated that menopausal status, older current age, and older age at the time of transplantation were associated with a decreased bone mass. The same study pointed that the longer the period after transplantation, the higher the bone mass of transplant recipients ${ }^{1}$. In contrast, a previous study identified that age and severity of liver disease, however not menopausal status, were the main risk factors for the development of osteoporosis in women with primary biliary cirrhosis, who were not liver-transplanted recipients ${ }^{8}$.

In the last few years, liver transplantation has become an efficient form of treatment for patients with severe liver disease. Advances in several aspects of medical transplantology have led to an increased survival of end-stage liver disease patients ${ }^{9}$. A larger number of women undergoing liver transplantation will therefore reach climacteric age. Most studies concerning hypogonadism after liver transplantation were based on male populations ${ }^{10}$. With the purpose of evaluating whether climacteric women undergoing liver transplantation had higher prevalence of decreased bone mass than those without history of liver disease, we conducted a study of women receiving outpatient treatment at a university hospital in Southeastern Brazil.

\section{Methods}

Cross-sectional study with women undergoing liver transplantation receiving treatment follow-up in the Liver Transplantation Outpatient Unit of the Hospital das Clínicas at University of Campinas (UNICAMP) Medical School, and those without liver disease receiving follow-up treatment in the Menopause Outpatient Unit of the Professor Doutor José Aristodemo Pinotti Women's Integ rated Healthcare Center (CAISM) of the UNICAMP Medical School, from February $4^{\text {th }} 2009$ to January $5^{\text {th }} 2011$. All women aged 35 years or older and who had undergone a liver transplantation at least one year before enrollment were included in the study. For each liver-transplant patient, a woman matched for age (three years, plus or minus) and for menstrual cycle pattern was selected for comparison. Women were considered postmenopausal when experiencing amenorrhea for at least 12 months or when folliclestimulating hormone (FSH) was higher than $23 \mathrm{mUI} / \mathrm{mL}$. Women were regarded as perimenopausal when presented menstrual irregularity (with no anatomical cause). Women presenting regular menstrual cycles were considered premenopausal ${ }^{11}$. We did not include patients who were in debilitating clinical conditions, those with personal history of bilateral oophorectomy or using hormone therapy for menopausal symptoms or contraception in the three months preceding the study. Thirty-three liver-transplant patients met the inclusion criteria. Of these, five did not respond to telephone contact and four declined to participate. The final number of transplant recipients participating in the study was 24 . For each liver- transplant patient, one woman without liver disease was selected, who was matched for age (three years, plus or minus) and menstrual cycle patterns. The final number of women included in the study was 48 .

Women had interviews in the Menopause Outpatient Facility at the CAISM of UNICAMP. Interviews were always performed by the same researcher in order to collect the following data: age; skin color; formal education; marital status; date of transplantation; period after transplantation; disease that caused liver failure; type of immunosuppressant drug currently 
in use; presence of arterial hypertension or diabetes mellitus; history of smoking; date of menarche; date of the last menstruation; menstrual cycle pattern; and sexual activity. Weight (kg), height (meters), and arterial blood pressure $(\mathrm{mmHg})$ were also measured. After the interview, blood samples were taken for laboratorial tests (FSH and serum estradiol), and BMD measurements at the lumbar spine and femur were performed. All patients signed a free written informed consent prior to the interview. The study was approved by the Research Ethics Committee of UNICAMP, under number $721 / 2008$, and funded by Fundação de Amparo à Pesquisa do Estado de São Paulo (FAPESP), under number 2008/09726-6.

\section{Bone mineral density}

Bone mineral density measurements at the lumbar spine (L1-L4), total femur, and femoral neck were made using a dual energy X-ray absorptiometry scan (Hologic, Discovery, WI). The variation coefficient of the device was $0.45 \%$. Bone mineral density measurements were expressed in grams per square centimeter $\left(\mathrm{g} / \mathrm{cm}^{2}\right)$ and as $\mathrm{T}$ - and $\mathrm{Z}$-scores. For BMD measurements, we used T-score value for postmenopausal and perimenopausal women. For premenopausal women, a Z-score was used ${ }^{12}$. T-score values lower or equivalent to -2.5 were classified as osteoporosis. The ones between -1 and -2.5 standard deviations were considered as low bone mass. Bone mass was considered normal for T-score values above or equal to-1 standard deviation ${ }^{13}$. Z-score values higher than -2 standard deviations were considered to be within the expected range for age, and $\mathrm{Z}$-score values equal or lower than -2 standard deviations were considered below the expected range for age ${ }^{12}$. For statistical analysis, values of T-score below -1 standard deviation and those of Z-score lower or equal to -2 standard deviations were considered as decreased bone mass. Values of T-score above or equal to -1 standard deviation and values of $\mathrm{Z}$-score above -2 standard deviations were considered as normal bone mass ${ }^{12,13}$.

\section{Biochemistry and hormone measurements}

After an overnight fast, blood samples were taken on the day of the interview from 7 to 10 o'clock A.M. The samples were stored in a freezer at $-20^{\circ} \mathrm{C}$ until processing. FSH measurement was obtained by chemiluminescence (Advia, Centauro-Siemens), with $0.3 \mathrm{mUI} / \mathrm{mL}$ as the minimum concentration detected. Concentrations higher than $23 \mathrm{mUI} / \mathrm{mL}$ were regarded as postmenopausal. Serum estradiol measurement was also obtained by chemiluminescence (Centauro-Siemens), and $7.0 \mathrm{pg} / \mathrm{mL}$ was the minimum concentration detected.

\section{Statistical analysis}

Data were assessed by mean, standard deviation, and median. For laboratory or time-interval measurements, the median was used as the cutoff point, and analysis was performed with categories above and below the median, using Fisher's exact test, simple Odds Ratio (OR), and multiple logistic regression analysis with stepwise variable selection. The significance level was set at $5 \%$ and SAS version 9.1.3 was the software used for analysis.

\section{Results}

The clinical social and demographic data of women included in this study are shown in Table 1 . The mean age was $52.8 \pm 10.7$ years-old (median 49.9, range 35.0-72.2). Among the patients, $6(12.5 \%)$ were 35 to 40 years-old, $6(12.5 \%)$ were 40 to 45 years-old, $12(25 \%)$ were 45 to 50 years-old, 2 (4.2\%) were 50 to 55 years-old, 7 $(14.6 \%)$ were 55 to 60 years-old, $6(12.5 \%)$ were 60 to 65 years-old, $8(16,7 \%)$ were 65 to 70 years-old, and 1 $(2.1 \%)$ was 70 to 75 years-old. The mean patient age at liver transplantation was $46.0 \pm 12.3$ years-old (median 43.4, range 25.7-63.9). The mean time since transplantation was $6.1 \pm 3.3$ years (median 5.8, range $1-12.5$ ). The mean body mass index was 27.6 44.7 (median 27.0, range 18.8-40.9). Of the 48 women, 13 (27.1\%) were premenopausal, $5(10.4 \%)$ were perimenopausal and 30 $(62.5 \%)$ were postmenopausal. Corticosteroid was used as an immunosuppressant agent by 8 women (16.7\%) and $40(83.3 \%)$ were not taking corticosteroid.

Among the 48 women included in the study, 24 had decreased bone mass (50\%). Of these, seven (14.6\%) had osteoporosis diagnosed by BMD measurement (with five $(10.4 \%)$ at one or more measured sites and two $(4.2 \%)$ at the lumbar spine, femoral neck and total femur), and 17 had low bone mass at one or more sites measured $(35.4 \%)$. Of the 24 liver-transplant recipients, $13(54.2 \%)$ had decreased bone mass, five $(20.8 \%)$ had osteoporosis diagnosed by BMD measurement at one or more sites measured, and $8(33.3 \%)$ had low bone mass at one or more sites measured. Of the 24 women without liver disease, 11 (45.8\%) had decreased bone mass, 2 $(8.3 \%)$ with osteoporosis diagnosed by BMD measurement at one or more sites measured and $9(37.5 \%)$ with low bone mass at one or more sites measured (Table 1 ).

Being postmenopausal $(\mathrm{OR}=71.4$; 95\% CI 3.8-1339.7; $\mathrm{p}<0.0001)$ was significantly associated with decreased bone mass. The age of woman at the time of the interview was significantly correlated, and age over 49 was highly associated with decreased bone mass $(\mathrm{OR}=11.4 ; 95 \% \mathrm{CI}$ $2.9-44.0 ; \mathrm{p}=0.0002)$. Serum estradiol levels lower than $44.5 \mathrm{pg} / \mathrm{mL}$ were also associated with decreased bone mass $(\mathrm{OR}=18.3$; 95\%CI 3.4-97.0; $\mathrm{p}<0.0001)$. 
Table 1. Clinical and social demographic data and bone mineral density, according to the World Health Organization criteria ( $\mathrm{n}=48$ )

\begin{tabular}{|c|c|c|c|c|c|c|c|c|}
\hline & \multicolumn{4}{|c|}{ Liver Transplantation } & \multicolumn{4}{|c|}{ Control } \\
\hline & \multicolumn{2}{|c|}{ Premenopausal } & \multicolumn{2}{|c|}{ Peri/postmenopausal } & \multicolumn{2}{|c|}{ Premenopausal } & \multicolumn{2}{|c|}{ Peri/postmenopausal } \\
\hline & $n$ & $\%$ & $n$ & $\%$ & n & $\%$ & $n$ & $\%$ \\
\hline \multicolumn{9}{|l|}{ Color } \\
\hline White & 7 & 100.0 & 13 & 76.5 & 2 & 33.3 & 11 & 61.1 \\
\hline Non-white & 0 & 0.0 & 4 & 23.5 & 4 & 66.7 & 7 & 38.9 \\
\hline \multicolumn{9}{|l|}{ Schooling } \\
\hline $8-12$ years & 2 & 28.6 & 5 & 29.4 & 2 & 33.3 & 4 & 22.2 \\
\hline$>12$ years & 1 & 14.3 & 2 & 11.8 & 0 & 0.0 & 0 & 0.0 \\
\hline \multicolumn{9}{|l|}{ Marital Status } \\
\hline With partner & 6 & 85.7 & 8 & 47.1 & 4 & 66.7 & 14 & 77.8 \\
\hline \multicolumn{9}{|l|}{ Hypertension } \\
\hline Yes & 7 & 100.0 & 9 & 52.9 & 5 & 83.3 & 11 & 61.1 \\
\hline \multicolumn{9}{|l|}{ Immunosupression } \\
\hline With corticosteroids & 4 & 57.1 & 4 & 23.5 & 0 & 0.0 & 0 & 0.0 \\
\hline \multicolumn{9}{|l|}{ Parity } \\
\hline 0 & 2 & 28.6 & 1 & 5.9 & 1 & 16.7 & 2 & 11.1 \\
\hline 1 & 4 & 57.1 & 5 & 29.4 & 3 & 50.0 & 2 & 11.1 \\
\hline$\geq 2$ & 1 & 14.3 & 11 & 64.7 & 2 & 33.3 & 14 & 77.8 \\
\hline \multicolumn{9}{|l|}{ Smoking } \\
\hline Yes & 1 & 14.3 & 0 & 0.0 & 1 & 16.7 & 2 & 11.1 \\
\hline Normal & 7 & 100.0 & 8 & 47.1 & 6 & 100.0 & 15 & 83.3 \\
\hline \multicolumn{9}{|l|}{ Lumbar spine (LI-L4) } \\
\hline Osteoporosis & 0 & 0.0 & 4 & 23.5 & 0 & 0.0 & 1 & 5.6 \\
\hline Low bone mass & 0 & 0.0 & 5 & 29.4 & 0 & 0.0 & 8 & 44.4 \\
\hline Normal & 7 & 100.0 & 8 & 47.1 & 6 & 100.0 & 9 & 50.0 \\
\hline
\end{tabular}

Osteoporosis: T-score $\leq-2.5$ standard-deviations; Low bone mass: T-score values between -1 and -2.5 standard-deviations; Normal: T-score > - 1 standard-deviation.

There was no statistically significant difference in bone mass values between the group with history of liver transplantation and the one without it $(\mathrm{OR}=1.4$; 95\% CI 0.4-4.3; $\mathrm{p}=0.5$ ).

All liver transplant recipients were taking immunosuppressant medication. Of these women, $8(16.7 \%)$ used tacrolimus and mycophenolate, $4(8.3 \%)$ used tacrolimus alone, $3(6.25 \%)$ used cyclosporine alone, 3 $(6.25 \%)$ used tacrolimus and prednisone, $1(2.1 \%)$ used cyclosporine and prednisone, $1(2,1 \%)$ used cyclosporine and mycophenolate, $2(4.2 \%)$ used tacrolimus, prednisone and mycophenolate, $1(2.1 \%)$ used cyclosporine, prednisone and mycophenolate, and $1(2.1 \%)$ used tacrolimus, prednisone and azathioprine. None of the study participants without liver disease used any type of immunosuppressant drug. Owing to a small sample, the diverse combinations of immunosuppressant agents and the fact that glucocorticoids are most strongly linked to decreased bone mass, we chose to subdivide these women into two groups. One of them was composed of steroid users (83.3\%), and the other did not use them $(16.7 \%)$. There was no significant difference between both groups concerning bone mass $(\mathrm{OR}=0.2$; 95\% CI 0.05-1.5; $\mathrm{p}=0.2$ ).

The associations between bone mass and skin color, marital status, arterial hypertension, diabetes mellitus, smoking, age at menarche, sexual activity, body mass index, and parity were not significant (Table 2). 


\begin{tabular}{|c|c|c|c|c|c|c|c|}
\hline & \multicolumn{4}{|c|}{ Bone mass } & \multirow{3}{*}{ p-value } & \multirow{3}{*}{ OR } & \multirow{3}{*}{$95 \% \mathrm{Cl}$} \\
\hline & \multicolumn{2}{|c|}{ Decreased } & \multicolumn{2}{|c|}{ Normal } & & & \\
\hline & $n$ & $\%$ & $n$ & $\%$ & & & \\
\hline Group & & & & & 0.56 & & \\
\hline Control & 11 & 45.8 & 13 & 54.2 & & 1.0 & \\
\hline Liver transplantation & 13 & 54.2 & 11 & 45.8 & & 1.4 & $0.4-4.3$ \\
\hline Age & & & & & $<0.01$ & & \\
\hline$\leq 49$ years-old & 5 & 20.8 & 18 & 75.0 & & 1.0 & \\
\hline$>49$ years-old & 19 & 79.2 & 6 & 25.0 & & 11.4 & $2.9-44.0$ \\
\hline Color & & & & & 0.11 & & \\
\hline White & 19 & 79.2 & 14 & 58.3 & & 2.7 & $0.7-9.7$ \\
\hline Non-white & 5 & 20.8 & 10 & 41.7 & & 1.0 & \\
\hline Marital status & & & & & 0.22 & & \\
\hline With partner & 14 & 58.3 & 18 & 75.0 & & 1.0 & \\
\hline Without partner & 10 & 41.7 & 6 & 25.0 & & 2.1 & $0.6-7.3$ \\
\hline Hypertension & & & & & 0.75 & & \\
\hline Yes & 8 & 33.3 & 7 & 29.2 & & 1.2 & $0.3-4.1$ \\
\hline No & 16 & 66.7 & 17 & 70.8 & & 1.0 & \\
\hline Diabetes mellitus & & & & & $0.41^{\star}$ & & \\
\hline Yes & 5 & 20.8 & 2 & 8.3 & & 2.8 & $0.5-16.6$ \\
\hline No & 19 & 79.2 & 22 & 91.7 & & 1.0 & \\
\hline Menopausal status & & & & & $<0.01^{\star}$ & & \\
\hline Premenopausal & 0 & 0.0 & 13 & 54.2 & & 1.0 & \\
\hline Perimenopausal & 2 & 8.3 & 3 & 12.5 & & 19.2 & $0.7-500.4$ \\
\hline Menopausal & 22 & 91.7 & 8 & 33.3 & & 71.4 & $3.8-1339.7$ \\
\hline Menarche & & & & & 0.55 & & \\
\hline$\leq 13$ years & 13 & 54.2 & 15 & 62.5 & & 1.0 & \\
\hline$>13$ years & 11 & 45.8 & 9 & 37.5 & & 1.4 & $0.4-4.4$ \\
\hline Sexual activity & & & & & 0.06 & & \\
\hline Yes & 13 & 54.2 & 15 & 62.5 & & 0.7 & $0.2-2.2$ \\
\hline No & 11 & 45.8 & 9 & 37.5 & & 1.0 & \\
\hline Body mass index & & & & & 0.24 & & \\
\hline$\leq 27$ & 14 & 58.3 & 10 & 41.7 & & 1.0 & \\
\hline$>27$ & 10 & 41.7 & 14 & 58.3 & & 0.5 & $0.1-1.6$ \\
\hline Immunosupression & & & & & $0.24^{\star}$ & & \\
\hline Without corticosteroids & 22 & 91.7 & 18 & 75.0 & & 1.0 & \\
\hline With corticosteroids & 2 & 8.3 & 6 & 25.0 & & 0.2 & $0.05-1.5$ \\
\hline Parity & & & & & $0.54^{\star}$ & & \\
\hline 0 & 2 & 8.3 & 4 & 16.7 & & 1.0 & \\
\hline 1 & 6 & 25.0 & 8 & 33.3 & & 1.3 & $0.2-8.7$ \\
\hline$\geq 2$ & 16 & 66.7 & 12 & 50.0 & & 2.3 & $0.4-13.1$ \\
\hline Estradiol & & & & & $<0.01$ & & \\
\hline$<44.5 \mathrm{pg} / \mathrm{mL}$ & 22 & 91.7 & 9 & 37.5 & & 18.3 & $3.4-97.0$ \\
\hline$\geq 44.5 \mathrm{pg} / \mathrm{mL}$ & 2 & 8.3 & 15 & 62.5 & & 1.0 & \\
\hline Smoking & & & & & $0.6^{*}$ & & \\
\hline Yes & 1 & 4.2 & 3 & 12.5 & & 1.0 & \\
\hline No & 23 & 95.8 & 21 & 87.5 & & 3.2 & $0.3-34.0$ \\
\hline
\end{tabular}

Decreased bone mass: T-score $<-1$ standard deviations or Z-score $\leq-2$ standard deviations. *Fisher's exact test. 


\section{Discussion}

The aim of this study was to assess whether climacteric women undergoing liver transplantation had higher prevalence of decreased bone mass than those without it. The prevalence rate of decreased bone mass (54.2\%) and osteoporosis $(20.8 \%)$ in women with a history of liver transplantation in the present study was slightly lower than the rate reported previously in the literature, which is around $65.5 \%$ of decreased bone mass ${ }^{14}$ and 25 to $50 \%$ of osteoporosis diagnosed by BMD measurement ${ }^{15,16}$. In the group of women without liver disease, the prevalence of decreased bone mass $(45.8 \%)$ was similar to that previously estimated, which is between 37 and $50 \%$ of the $\operatorname{cases}^{17}$. There were no significant differences between the rates of decreased bone mass in women with a search history of liver transplantation and those without a search history.

Previous data have shown that loss of bone mass occurs especially in the first three to six months following liver transplantation ${ }^{18-20}$. Studies of bone histology have shown that bone loss ceases approximately six months after liver transplantation. Bone formation tends to increase later, especially at the lumbar spine, leading to restoration of bone mass up to two years after surgery ${ }^{9}$. A previous study ${ }^{1}$ showed a clear tendency towards increased bone mass at the lumbar spine, as time since transplantation increased. The same study observed a less intense correlation between bone mass at the femoral neck and time since transplantation. Previous studies showed that restoration of bone mass was slower at the femoral neck than at the lumbar spine. It is likely that cortical bone requires more time to recover than the trabecular one $\mathrm{e}^{14,18}$. The mean time since transplantation in the present study was $6.1 \pm 3.3$ years. We believe that a high mean time elapsed since surgery was the major factor associated with the lack of a significant difference in bone mass, between liver transplant patients and the nontransplant ones.

The relationship between menopausal status and bone mass in patients with chronic liver disease is not fully understood. A study with subjects who had received a liver transplant observed correlations between menopausal status and chronological age. However, the authors did not observe a significant influence of menopausal status on bone mass ${ }^{18}$. A study including nontransplant patients with primary biliary cirrhosis concluded that menopausal status was not an independent risk factor for osteoporosis, however independent factors were chronological age, severity of liver disease, advanced histologic stage, and low body mass index ${ }^{8}$. A more recent study with only women undergoing liver transplantation found an inverse correlation between BMD and length of amenorrhea expressed in months after the last menstruation, i.e., the longer the time since onset of menopause, the lower the $\mathrm{BMD}^{1}$. Decreased bone mass was not observed in any premenopausal women, regardless of receiving or not a liver transplant. In perimenopausal and postmenopausal women with history of liver transplantation, decreased bone mass was found in $76.5 \%$ of the cases, and osteoporosis was diagnosed in $29.4 \%$ of them.

The prevalence of osteoporosis in climacteric transplant recipients in the present study was lower than the result reported by a previous study, which described osteoporosis in 50\% of patients undergoing liver transplantation in the postmenopause. However, it is worth mentioning that in this study approximately $94 \%$ of climacteric transplant recipients were taking glucocorticoids ${ }^{16}$. In contrast, only $23.5 \%$ of them were using corticosteroids in the present study. In control perimenopausal and postmenopausal women, decreased bone mass was present in $61.1 \%$, and osteoporosis was diagnosed by BMD measurement in $11.1 \%$ of women. We observed a significant association between postmenopausal status, serum estradiol levels lower than $44.5 \mathrm{pg} / \mathrm{mL}$, and decreased bone mass. Such data have led us to believe that menopausal status is indeed one of the main factors associated with higher prevalence of decreased bone mass, both in liver transplant patients and in women without a history of liver disease. A noteworthy result observed in the present study was that there was no decreased bone mass in any of the premenopausal women undergoing transplantation. This finding is in agreement with previously reported data in the literature, which indicates that gain in bone mass during the first two years after transplantation was significantly higher in premenopausal women compared to that observed in perimenopausal and postmenopausal patients, probably due to high estrogen levels in these women ${ }^{19}$.

The deleterious effect of glucocorticoids on bone mass has already been previously demonstrated ${ }^{21-29}$. In the present study, the current use of corticosteroid as an immunosuppressant did not affect bone mass in liver transplant recipients, probably due to time elapsed since the transplant. Similar results were also obtained in previous studies $^{14,18,19}$. A likely explanation for this finding could be that high-dose steroid therapy is administered especially in the first months following transplantation, causing a higher loss of bone mass in the first months after the procedure ${ }^{26}$. In the following years, the trend will be to decrease the total dose of glucocorticoids used, mainly because of its combination with tacrolimus ${ }^{28,30}$, resulting in a less significant influence on bone mass. The effects of reduced total dose of glucocorticoids could already be 
observed in a recent study that found decreased incidence of fractures in patients undergoing liver transplantation, in the period from 1998 to $2008^{5}$.

We highlight that this study assessed women with positive history of liver transplantation aged 35 years or older and a Control Group with negative history of liver disease, matched for age and menstrual cycle pattern. The number of subjects included in each subgroup was small, which can reduce the strength of statistical results and cannot be generalized to other groups of liver transplant recipients or other populations. However, we believe that a comparison of a group of women with history of liver transplantation and a group of women with healthy livers is of great importance to better comprehend hypogonadism following transplantation and its interference in bone mass.

The present study showed that menopausal status, older current age, and lower serum estradiol levels were the major factors associated with decreased bone mass in the female group evaluated. There was no difference in BMD between the group with history of liver transplantation and the Control Group, probably due to a high mean time period after transplantation in the transplant recipient group. This topic has still not been thoroughly studied and fully understood. We believe that reported data may help to understand the behavior of bone mass in women undergoing liver transplantation. Further studies are necessary, since the number of transplantations performed continues to grow.

\section{Acknowledgements}

We thank Sirlei Siani Moraes for the statistical analysis. This work was supported by Fundação de Amparo à Pesquisa do Estado de São Paulo (FAPESP), process 2008/09726-6.

\section{References}

1. Baccaro LF, Boin IF, Pedro AO, Costa-Paiva L, Leal AG, Ramos CD, et al. Decrease in bone mass in women after liver transplantation: associated factors. Transplant Proc. $2011 ; 43(4): 1351-6$.

2. Hommann M, Kammerer D, Lehmann G, Kornberg A, Kupper B, Daffner $W$, et al. Prevention of early loss of bone mineral density after liver transplantation by prostaglandin E1. Transplant Proc. 2007;39(2):540-3.

3. Monegal A, Navasa M, Guañabens N, Peris P, Pons F, Martinez de Osaba M, et al. Osteoporosis and bone mineral metabolism disorders in cirrhotic patients referred for orthotopic liver transplantation. Calcif Tissue Int. 1997;60(2): 148-54.

4. Newton J, Francis R, Prince $M$, James $O$, Bassendine $M$, Rawlings $D$, et al. Osteoporosis in primary biliary cirrhosis revisited. Gut. 2001;49(2):282-7.

5. Preamor MO, Das TK, Debiram I, Parker RA, Ninkovic M, Alexander GT, et al. Fracture incidence after liver transplantation: results of a 10-year audit. QJM. 2011;104(7):599-606

6. Jabiry-Zienjewicz Z, Kaminski P, Bobrowska K, Pietrzak B, Wielgos $M$, Zieniewicz K, et al. Menstrual cycle and sex hormone profile in perimenopausal women after liver transplantation. Transplant Proc. 2006;38(9):2909-12.

7. Boin IF, Ataide EC, Leonardi MI, Stucchi R, Sevá-Pereira T, Pereira IW, et al. Elderly donors for $\mathrm{HCV}(+)$ versus non-HCV recipients: patient survival following liver transplantation. Transplant Proc. 2008;40(3):792-6.

8. Guañabens N, Parés A, Ros I, Caballeria L, Pons F, Vidal S, et al. Severity of cholestasis and advanced histological stage but not menopausal status are the major risk factors for osteoporosis in primary biliary cirrhosis. J Hepatol. 2005;42(4):573-7.

9. Lim KB, Schiano TD. Long-term outcome after liver transplantation. Mt Sinai J Med. 2012;79(2):169-89.

10. Compston JE. Osteoporosis after liver transplantation. Liver Transpl. 2003;9(4):321-30.
11. Birkhauser MH, Barlow DH, Notelovitz M, Rees MC. Management handbook: health plan for the adult woman. London: Taylor \& Francis; 2005.

12. Baim S, Binkley N, Bilezikian JP, Kendler DL, Hans DB, Lewiecki $E M$, et al. Official Positions of the International Society for Clinical Densitometry and executive summary of the 2007 ISCD Position Development Conference. J Clin Densitom. 2008; 11 (1): 75-91.

13. World Health Organization. Assessment of fracture risk and its application to screening for postmenopausal osteoporosis. Report of a WHO Study Group. World Health Organ Tech Rep Ser. 1994;843:1-129.

14. Segal E, Baruch Y, Kramsky R, Raz B, Tamir A, Ish-Shalom S. Predominant factors associated with bone loss in liver transplant patients - after prolonged post-transplantation period. Clin Transplant. 2003;17(1):13-9.

15. Giannini S, Nobile M, Dalle Carbonare L, Ciuffreda M, Germoni V, lemmolo RM, et al. Vertebral morphometry by X-ray absorptiometry before and after liver transplant: a crosssectional study. Eur J Gastroenterol Hepatol. 2001;13(10): 1201-7.

16. Isoniemi H, Appelberg J, Nilsson CG, Makela P, Risteli J, Hockerstedt K. Transdermal oestrogen therapy protects postmenopausal liver transplant women from osteoporosis. A 2-year follow-up study. J Hepatol. $2001 ; 34(2): 299-305$.

17. Sokhi RP, Anantharaju A, Kondaveeti R, Creech SD, Islam KK, Van Thiel $\mathrm{DH}$. Bone mineral density among cirrhotic patients awaiting liver transplantation. Liver Transpl. 2004; 10(5):648-53.

18. Monegal A, Navasa M, Guañabens N, Peris P, Pons F, Martinez de Osaba M, et al. Bone disease after liver transplantation: a long-term prospective study of bone mass changes, hormonal status and histomorphometric characteristics. Osteoporos Int. $2001 ; 12(6): 484-92$ 
19. Guichelaar MM, Kendall R, Malinchoc M, Hay JE. Bone mineral densitiy before and after OLT: long-term follow-up and predictive factors. Liver Transpl. 2006;12(9):1390-402.

20. Hay JE. Osteoporosis in liver diseases and after liver transplantation. J Hepatol. 2003;38(6):856-65.

21. Torregrosa JV, Campistol JM, Montesinos M, Fenollosa B, Pons $F$, Martinez de Osaba M, et al. Factors involved in the loss of bone mineral density after renal transplantation. Transplant Proc. $1995 ; 27(4): 2224-5$.

22. Goldstein MF, Fallon JJ Jr, Harning R. Chronic glucocorticoid therapy-induced osteoporosis in patients with obstructive lung disease. Chest. 1999; 116(6):1773-49

23. Weinstein RS, Jilka RL, Parfitt AM, Manolagas SC. Inhibition of osteoblastogenesis and promotion of apoptosis of osteoblasts and osteocytes by glucocorticoids. Potential mechanisms of their deleterious effects on bone. J Clin Invest. 1998; 102(2):274-82.

24. Weinstein RS, Chen JR, Powers CC, Stewart SA, Landes RD, Bellido T, et al. Promotion of osteoclast survival and antagonism of bisphosphonate-induced osteoclast apoptosis by glucocorticoids. J Clin Invest. 2002;109(8):1041-8.
25. Morris HA, Need AG, O'Loughlin PD, Horowitz M, Bridges A, Nordin BE. Malabsortion of calcium in corticosteroid-induced osteoporosis. Calcif Tissue Int. 1990;46(5):305-8.

26. Sambrook P, Birmingham J, Kempler S, Kelly P, Eberl S, Pocock N, et al. Corticosteroid effects on proximal femur bone loss. J Bone Miner Res. 1990;5(12):1211-6.

27. Van Staa TP, Leufkens HG, Abenhaim L, Zhang B, Cooper C. Use of oral corticosteroids and risk of fractures. J Bone Miner Res. 2000; 15(6):993-1000.

28. Monegal A, Navasa M, Guañabens N, Peris P, Pons F, Martínez de Osaba $M$, et al. Bone mass and mineral metabolism in liver transplant patients treated with FK506 or cyclosporine A. Calcif Tissue Int. $2001 ; 68(2): 83-6$.

29. Diaz-Guerra GM, Gómez R, Jódar E, Loinaz C, Moreno E, Hawkins F. Long-term follow-up of bone mass after orthotopic liver transplantation: effect of steroid withdrawal from the immunosuppressive regimen. Osteoporos Int. 2002;13(2): 147-50.

30. Stein E, Ebeling P, Shane E. Post-transplantation osteoporosis. Endocrinol Metab Clin North Am. 2007;36(4):937-63. 